\title{
EXISTENCE OF SOLUTIONS FOR A SINGULAR FOURTH-ORDER $p$-LAPLACIAN SYSTEM
}

\author{
Kamal Bachouche, Smaïl DJebali and Toufik Moussaoui
}

Abstract. This work is devoted to proving existence of solutions for a singular fourth-order $p$ Laplacian system. The nonlinearities depend on the solution and first derivatives and may exhibit singularities. Existence results are proved using the Leray-Schauder nonlinear alternative. Examples of applications illustrate each one of the obtained results.

Mathematics subject classification (2010): 47H10, 34B15, 34B18.

tem.

Keywords and phrases: fourth-order BVPs, $p$-Laplacian problem, nonlinear alternative, singular sys-

\section{REFERENCES}

[1] R.P. AgARWAL, On fourth-order boundary value problems arising in beam analysis, Diff. Integ. Equ. 2 (1989), 91-110.

[2] R.P. Agarwal, H. LÜ, D. O'Regan, Positive solutions for the boundary-value problem $\left(\left|u^{\prime \prime}\right|^{p-2} u^{\prime \prime}\right)^{\prime \prime}=\lambda q(t) f(u)$, Mem. Diff. Equ. Math. Phys, 28 (2003), 33-44.

[3] Z. BAI, H. WANG, On positive solutions of some nonlinear fourth-order beam equations, J. Math. Anal. Appl., 270 (2002), 357-368.

[4] A. Benmezai, S. Djebali, T. Mouss aoui, Positive solutions for $\phi$-Laplacian Dirichlet BVPs, Fixed Point Theory, 8(2) (2007), 167-186.

[5] A. Benmezai, S. Djebali, T. Moussaoui, Multiple positive solutions for $\phi$-Laplacian BVPs, PanAmer. Math. J., 17, 3 (2007), 53-73.

[6] S. Djebali, T. Moussaoui, R. Precup, Fourth-order p-Laplacian nonlinear systems via the vector version of Krasnosel'skiï's fixed point theorem, Mediterr. J. Math., 6 (2009), 447-460.

[7] A. Granas, J. Dugundu, Fixed Point Theory, Springer Monographs in Mathematics, Springer, New York, 2003.

[8] C.P. GuPTA, Existence and uniqueness results for the bending of an elastic beam equation at resonance, J. Math. Anal. Appl., 135 (1988), 208-225.

[9] C.P. GuPTA, Existence and uniqueness theorems for the bending of an elastic beam equation, Appl. Anal., 26 (1988), 289-304.

[10] D.D. HAI, H. WANG, Nontrivial solutions for p-Laplacian systems, J. Math. Anal. Appl., 330, 1 (2007), 186-194.

[11] J. Henderson, H. WAng, An eigenvalue problem for quasilinear systems, Rocky Mountain J. Math., 37, 1 (2007), 215-228.

[12] R.Y. MA, H. WANG, On the existence of positive solutions of fourth-order ordinary differential equations, Anal. Appl., 59 (1995), 225-231.

[13] R. PRECUP, A vector version of Krasnosel'skit's fixed point theorem in cones and positive periodic solutions of nonlinear systems, J. Fixed Point Theory Appl. 2, 1 (2007), 141-151.

[14] R. Song, H. LÜ, Positive solutions for singular nonlinear beam equation, Electronic Journal of Differential Equations, 3 (2007), 1-9.

[15] Y. YANG, Fourth-order two-point boundary value problem, Proc. Amer. Math. Soc., 104 (1988), 175180.

[16] E. ZeIdLeR, Nonlinear Functional Analysis and its Applications. Vol. I: Fixed Point Theorems, Springer-Verlag, New York, 1986. 
[17] Y. ZHU, P. WENG, Multiple positive solutions for a fourth-order boundary value problem, Bol. Soc. Paran. Mat. (3s.) V. 21 1/2 (2003), 1-10. 